\title{
Determining the Optimal Time to Launch an Emerging Innovation in a Market
}

\begin{abstract}
Investments in emerging technologies and the development of related emerging innovations are necessary to compete in the long term. The market entry timing plays an important role in generating decisive competitive advantages over competitors through investments in emerging innovations. Different market entry strategies offer varied opportunities and risks, which firms must take into account when choosing the optimal time to enter the market. This study develops an optimisation model to make an economically appropriate ex-ante decision in this choice by accounting for several relevant factors and weighing up possible opportunities and risks of the chosen market entry strategy. The evaluation of the simulation results shows that the considered factors influence the optimal market entry to varying extents, and that both early and late market entry can be advantageous for companies.
\end{abstract}

Keywords: Emerging Innovation; Innovation Diffusion; Market Entry Timing; First-Mover; LateMover; Norton-Bass-Model 